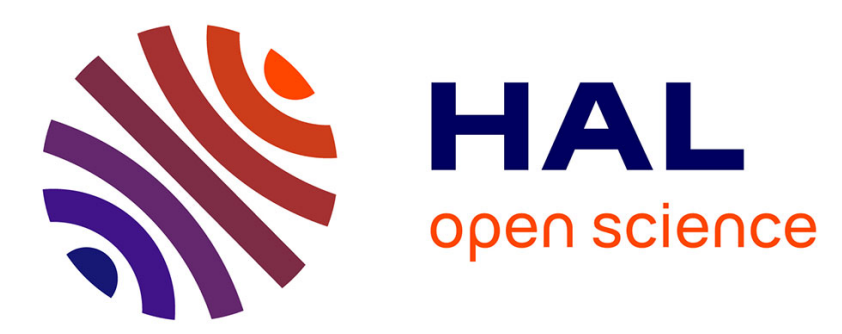

\title{
Deciphering structural and temporal interplays during the architectural development of mango trees
}

Anaëlle Dambreville, Pierre-Eric Lauri, Catherine Trottier, Yann Guédon, Frédéric Normand

\section{- To cite this version:}

Anaëlle Dambreville, Pierre-Eric Lauri, Catherine Trottier, Yann Guédon, Frédéric Normand. Deciphering structural and temporal interplays during the architectural development of mango trees. Journal of Experimental Botany, 2013, 64 (8), pp.2467-2480. 10.1093/jxb/ert105 . hal-00806978

\section{HAL Id: hal-00806978 \\ https://hal.science/hal-00806978}

Submitted on 28 May 2020

HAL is a multi-disciplinary open access archive for the deposit and dissemination of scientific research documents, whether they are published or not. The documents may come from teaching and research institutions in France or abroad, or from public or private research centers.
L'archive ouverte pluridisciplinaire HAL, est destinée au dépôt et à la diffusion de documents scientifiques de niveau recherche, publiés ou non, émanant des établissements d'enseignement et de recherche français ou étrangers, des laboratoires publics ou privés. 


\title{
Deciphering structural and temporal interplays during the architectural development of mango trees
}

\author{
Anaëlle Dambreville ${ }^{1,2}$, Pierre-Éric Lauri ${ }^{2}$, Catherine Trottier ${ }^{3}$, Yann Guédon ${ }^{4}$ and Frédéric Normand ${ }^{1, *}$ \\ 1 CIRAD, UPR HortSys, 97455 Saint-Pierre Cedex, Réunion Island, France \\ 2 INRA, UMR AGAP, 34098 Montpellier, France \\ ${ }^{3}$ Université Montpellier II, UMR I3M, \#5149, Equipe 'Probabilités et Statistique', 34095 Montpellier, France \\ ${ }^{4}$ CIRAD, UMR AGAP and INRIA, Virtual Plants, 34095 Montpellier, France \\ * To whom correspondence should be addressed. E-mail: frederic.normand@cirad.fr
}

Received 22 January 2013; Revised 19 March 2013; Accepted 19 March 2013

\begin{abstract}
Plant architecture is commonly defined by the adjacency of organs within the structure and their properties. Few studies consider the effect of endogenous temporal factors, namely phenological factors, on the establishment of plant architecture. This study hypothesized that, in addition to the effect of environmental factors, the observed plant architecture results from both endogenous structural and temporal components, and their interplays. Mango tree, which is characterized by strong phenological asynchronisms within and between trees and by repeated vegetative and reproductive flushes during a growing cycle, was chosen as a plant model. During two consecutive growing cycles, this study described vegetative and reproductive development of 20 trees submitted to the same environmental conditions. Four mango cultivars were considered to assess possible cultivar-specific patterns. Integrative vegetative and reproductive development models incorporating generalized linear models as components were built. These models described the occurrence, intensity, and timing of vegetative and reproductive development at the growth unit scale. This study showed significant interplays between structural and temporal components of plant architectural development at two temporal scales. Within a growing cycle, earliness of bud burst was highly and positively related to earliness of vegetative development and flowering. Between growing cycles, flowering growth units delayed vegetative development compared to growth units that did not flower. These interplays explained how vegetative and reproductive phenological asynchronisms within and between trees were generated and maintained. It is suggested that causation networks involving structural and temporal components may give rise to contrasted tree architectures.
\end{abstract}

Key words: asynchronism, growth unit, Mangifera indica, phenology, plant architecture, reproductive development, vegetative development.

\section{Introduction}

Plant architecture is commonly defined by the nature and the structural arrangement of plant entities, i.e. topology (connection between entities) and geometry (form of plants) (Hallé et al., 1978; Bell, 1991; Barthelemy and Caraglio, 2007). It is the result of the balance between endogenous processes and exogenous constraints. Various structural scales are used to describe plant architecture (Godin et al., 1999), including the growth unit (GU), which is defined as the portion of the axis developed during an uninterrupted period of growth (Hallé and Martin, 1968).

Plant architecture is established over time, suggesting a temporal component in architectural development. This aspect is investigated through the concept of phenology that deals with the periodicity of recurrent biological events of 
living organisms (Newstrom et al., 1994; Sakai, 2001). In the case of trees, these events, referred to as 'phenological stages', encompass the consecutive steps of vegetative (leaf flushing, growth arrest) and reproductive (flowering, fruiting) development from bud burst to growth arrest (Lieth, 1974). Phenology is generally studied in relation to climatic parameters (temperature, rainfall), and its interest has been consistently renewed in past decades to assess the effect of climate change on plants (Guédon and Legave, 2008; Körner and Basler, 2010). In temperate areas, tree phenology is globally synchronized at the year scale due to cold winter conditions. In tropical and subtropical areas, phenological stages are spread out over time, not only between neighbouring trees but also within a tree (Scarrone, 1969; Borchert, 1991; Sakai, 2001). Such asynchronisms suggest that tropical tree phenology is markedly influenced by endogenous tree traits.

The phenology of flowering and fruiting is partly controlled by genetically determined mechanisms (SmithRamírez et al., 1998; Marco and Páez, 2002). Quantitative trait loci have been identified for the timing of leaf flush and flowering (Bradshaw and Stettler, 1995; Celton et al., 2011). However, phenological variations between branches within a tree crown and between neighbouring genetically identical trees (e.g. vegetatively propagated trees in an orchard) cannot be explained by genetic variables. For example, at the axis or GU scale, the flushing growth pattern of litchi appears to be more governed by endogenous architectural variables (type and age of axes, number of GUs per branch, etc.) than by environmental ones (Costes, 1995). Moreover, a relationship has been identified in forest tree saplings between the phenology of leafing and shoot inclination: upright shoots have a more spread leaf phenology than slanting shoots (Kikuzawa et al., 1996). Several studies also revealed that distal buds along a GU, i.e. in an acrotonic position, appear and flower earlier and grow more than buds that develop in a proximal position (Champagnat et al., 1971; Lauri, 2007). However, as far as is known, no comprehensive study of how structural and temporal components are combined to determine vegetative and reproductive patterns within a tree canopy exists at this time.

Mango (Mangifera indica L.) is one of the most widely cultivated and popular fruits in the tropics and subtropics, and represents the fifth most cultivated fruit in the world, with 33.7 million tons of fruit produced in 2009 (Gerbaud, 2011). It is an evergreen tropical tree that belongs to the architectural model of Scarrone, defined, among other traits, by rhythmic growth and terminal flowering (Hallé et al., 1978). Rhythmic growth takes form as a succession of GUs separated by scars of bud scales and very short internodes that indicate the location of the resting bud. Mango vegetative growth, flowering, and fruiting appear in the whole canopy as flushes, either in synchrony or asynchronically (Chacko, 1986; Ramírez and Davenport, 2010). This suggests that although organ development is closely related to temperature (Bonhomme, 2000; Dambreville et al., 2013), vegetative and reproductive development in mango is, for a large part, governed by endogenous factors and not just by environmental cues. In this way, some studies on mango showed that an old GU bursts earlier (Scholefield et al., 1986) and has a higher occurrence of flowering (Scholefield et al., 1986; Davenport, 2000; Jannoyer and Lauri, 2009) than a more recent GU. It has also been shown that reiterated complexes, which are repetitions of parts or of the whole sequence of the tree architectural model (Hallé et al., 1978), have a phenology that differs from the rest of the tree (Goguey, 1997).

This study hypothesized that the actual mango tree architecture results from both structural and temporal components of development, and from their interplays. Thus, an experiment was designed in which the development of 20 mango trees at the GU scale was monitored. Two integrative models were built for analysing either vegetative or reproductive development. The nature and the arrangement of the models' components were not based on biological processes. They were elementary events describing the occurrence, the intensity, and the timing of vegetative and reproductive development. Two questions were addressed on the basis of these analyses: (i) How do structural and temporal components determine vegetative and reproductive developmental patterns? and (ii) Can these interplays explain between- and within-tree asynchronisms? In the latter case, the hypothesis that competition between organs, as well as endogenous rhythms, trigger and maintain asynchronisms within the tree crown is discussed.

\section{Materials and methods}

\section{Field site and plant material}

The experimental orchard was located at the CIRAD (French Agricultural Research Centre for International Development) Research Station in Saint-Pierre, Réunion Island (21 $31^{\circ} \mathrm{S}$ and $55^{\circ}$ $51^{\prime}$ E, altitude $280 \mathrm{~m}$ ). The orchard consisted of 112 trees of eight mango cultivars (14 trees per cultivar) grafted onto a polyembryonic rootstock, 'Maison Rouge'. Trees were planted in May 2001, with a distance of $6 \mathrm{~m}$ between rows and $4 \mathrm{~m}$ within the row, in eight lines of 14 trees belonging to two cultivars. They were first harvested at the beginning of the study, i.e. at the end of 2003. To avoid any effect of manipulation on tree architecture, trees were not pruned during the study. They were drip-irrigated from fruit set (August) to the beginning of the rainy season (December). All trees were submitted to the same environmental conditions during the experiment. An automatic weather station located close to the orchard recorded temperatures during the whole experiment (Fig. 1A).

Four cultivars characterized by their contrasting architectural and fruiting patterns were chosen: Cogshall and José that are extensively grown in Réunion Island and Irwin and Kensington Pride that are extensively grown in producing countries for local and international markets.

The growing cycle was defined as the period composed of the succession of a vegetative development period (Fig. 1B, VD), i.e. appearance of new GUs, and a reproductive development period, i.e. flowering (Fig. 1B, Flo) and possibly fruiting (Fig. 1B, Fr) on these GUs in terminal position. At the study site, vegetative development occurs through consecutive flushes from August to May. June is the resting period (Fig. 1B, VR) before flowering, which occurs in one to three flushes from July to October. Inflorescences are temporary organs that do not remain in the tree structure; they dry up and fall off. Only some inflorescences set fruit. In this case, the fruiting phase extends from fruit set to harvest. The harvest may last 1 or 2 months on the same tree. The mango growing cycle thus lasts for 1.5 years, from the beginning of vegetative development to the end of harvest. The beginning of vegetative development of a growing cycle is concomitant with the flowering and fruiting phases of the previous growing cycle. 

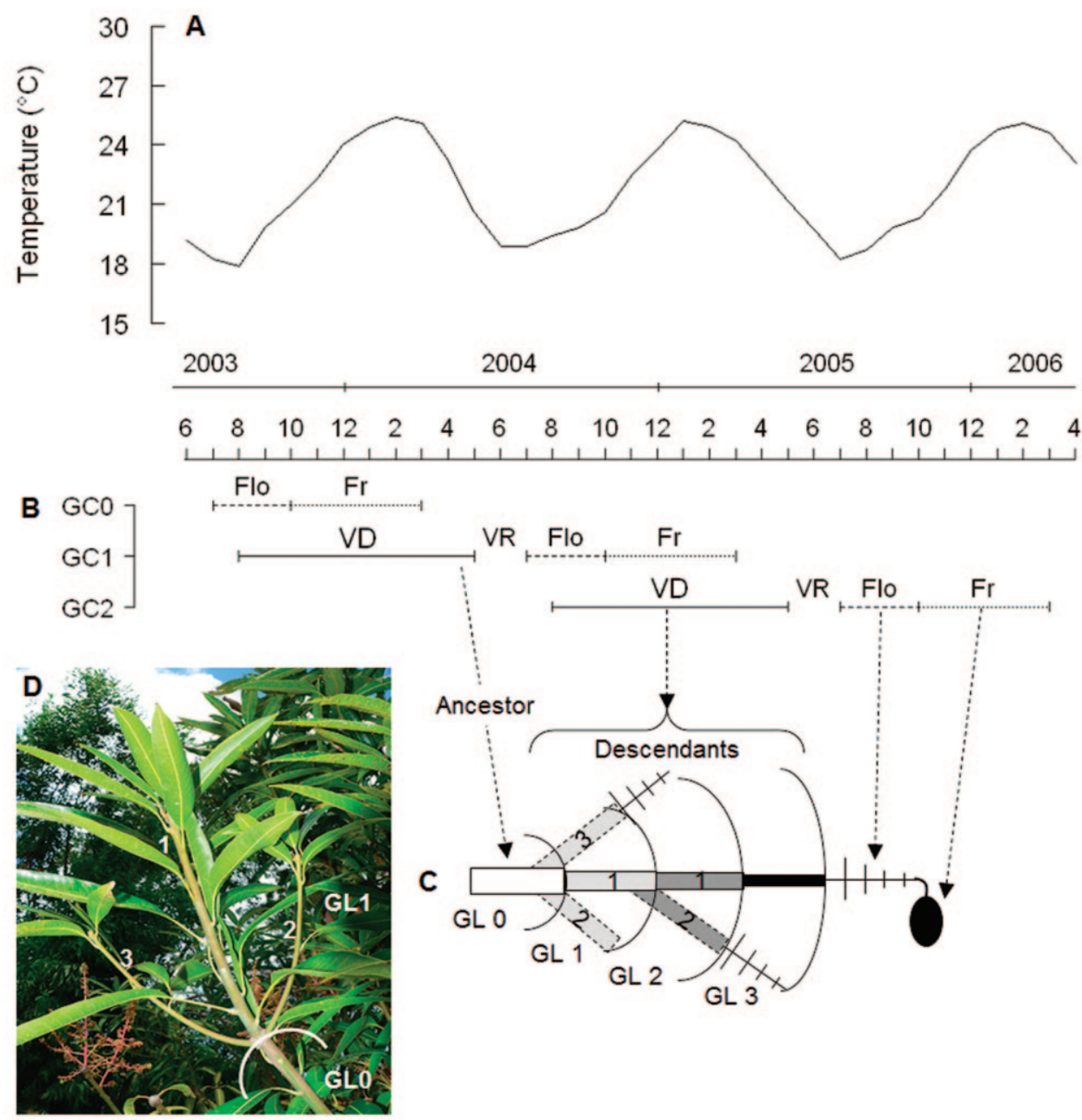

Fig. 1. Temperature conditions in the experimental orchard and relationships between temporal and topological successions of growth units (GUs) during mango tree development. (A) Monthly mean air temperature from June 2003 to April 2006. (B) Temporal succession of three growing cycles (GCs: GC0, GC1, GC2) of mango trees. Each GC is composed of a succession of a vegetative development period (VD), a vegetative rest period (VR), flowering (Flo), and fruiting (Fr: fruit growth until harvest). (C) Topological and temporal development of GUs during GC2 stemming from a vegetative ancestor GU grown during GC1 (white rectangle). Rectangles are GUs; leaves are not represented. Fishbone-like symbols are inflorescences. A GU can be in apical (solid line) or lateral (dotted line) position on the supporting GU. Grey shading represents consecutive dates of burst of GUs during GC2: light grey for early GUs to black for late GUs. Growth levels (GLs) are numbered according to the order of development from the beginning of the growing cycle (GL1, GL2, GL3). Numbers in rectangles are used to identify GUs of a same GL. (D) Picture illustrating mango GUs, with an ancestor GU (GLO) and three direct descendant GUs, one apical ('1') and two laterals ('2', ' 3 '), at the first growth level (GL1) (this figure is available in colour at JXB online).

The plant materials in this study were GUs. Each GU could be characterized from two complementary points of view: temporal (when it grows during the growing cycle), and structural (where it grows, i.e. its topological position). The growth level (GL) was defined as the topological rank of GUs produced during a growing cycle (GL1-GL3 in Fig. 1C). At the end of a growing cycle, the growth level thus reflected the position of the GU within the canopy, a GU of a lower growth level being located more deeply within the canopy. The GUs produced during a growing cycle were generally distributed over one or two growth levels (maximum of five).

This study used the terminology of kinship, e.g. ancestor/descendant and mother/daughter, to describe the topological adjacency and the temporal succession between GUs. The last GU developed during a growing cycle, referred to as the ancestor GU (Fig. 1C, white), will support the sequence of new GUs produced during the next growing cycle, referred to as its descendant GUs (Fig. 1C, grey and black shading). By convention, the ancestor $\mathrm{GU}$ is located at growth level 0. Among these descendant GUs (within the same growing cycle), GUs that produce one to several daughter GUs (e.g. Fig. 1C: GL2, GU1 and GU2) are referred to as mother GUs (e.g. Fig. 1C: GL1, GU1). GUs stemming from the same mother GU are considered as sister GUs and generally appear during the same flush (e.g. Fig. 1C: GL2, GU1 and GU2 are sister GUs). The rhythmic growth of mango trees thus leads to highly interwoven structural and temporal development components.

\section{Data collection and variables studied}

The experiment was carried out during two consecutive growing cycles: from the beginning of vegetative development in August 2003 to the end of the harvest in March 2005, hereafter referred to as the first growing cycle (Fig. 1B, GC1), and from the beginning of vegetative development in August 2004 to the end of the harvest in March 2006, hereafter referred to as the second growing cycle 
(Fig. 1B, GC2). For each cultivar, five healthy trees were selected, for a total of 20 trees studied. To study the possible interactions between reproductive and vegetative developments, and between the reproductive developments of consecutive growing cycles (alternate bearing of mango; Monselise and Goldschmidt, 1982), all of the fruits of two out of the five trees were thinned at fruit set during the two growing cycles. These trees were referred to as thinned trees. The three other trees were unthinned trees.

This study exhaustively described all GUs that appeared from sequential growth, i.e. located at the periphery of the canopy, of the 20 trees studied. Data were collected once a month, at the same period within the month, and all of the GUs that appeared during the elapsed month were considered. Each GU was described using three categories of traits related to the occurrence, the intensity, and the timing of vegetative and reproductive development. Qualitative traits were the position with regard to the supporting GU (apical, i.e. stemming from the apical meristem, or lateral, i.e. stemming from an axillary meristem, Fig. 1C) and the fate (vegetative if it did not produce any inflorescence, or reproductive if it produced at least one inflorescence, with or without fruit set). Quantitative traits were numbers of daughter GUs and inflorescences borne. Temporal traits were the date of burst of vegetative buds (at the monthly scale) and the date of flowering (date of full bloom, i.e. approximately $50 \%$ of all flowers of the inflorescence open, aggregated every 2 weeks).

\section{Data analysis}

The traits studied were encoded as discrete variables of different natures: binary variables for qualitative traits, count variables for quantitative traits, and ordinal variables for temporal traits. Temporal traits were considered as ordinal data because the dates of observation were not strictly evenly spaced (approximately every month for the dates of burst and every 2 weeks for the dates of flowering). The terms 'early' and 'late' refer to the beginning and the end of the period considered, respectively. An appropriate categorical or count distribution was then selected for each variable: binomial distribution for binary variables, Poisson distribution for count variables, and ordinal multinomial distribution for ordinal variables.

For each cultivar and each growing cycle, two integrative models were built, one for vegetative development and the other for reproductive development (Fig. 2). Generalized linear models (GLMs) were used as components of both of these integrative models. The use of simple regression models such as GLMs limited the type of dependencies between GUs that could be modelled (e.g. dependencies between sister GUs could only be modelled as the global effect of the number of sister GUs of a given GU). These integrative models could be represented as oriented tree graphs where each vertex represented the response variable of a GLM (Fig. 2). Each thin solid arrow represented the conditioning of a subsequent GLM by the value 1 (true) taken by the binary response variable of a binomial model. Because of the heterogeneity of the response variables (binomial, Poisson, and ordinal multinomial models) and the conditioning between successive GLMs, each individual GLM was estimated separately. The two integrative models should therefore be considered as conceptual models, each with a set of specific response variables, aiming at giving a coherent view of the vegetative and reproductive developments. The integrative modelling approach proposed is somewhat related to the approach of Pearl (2009) since

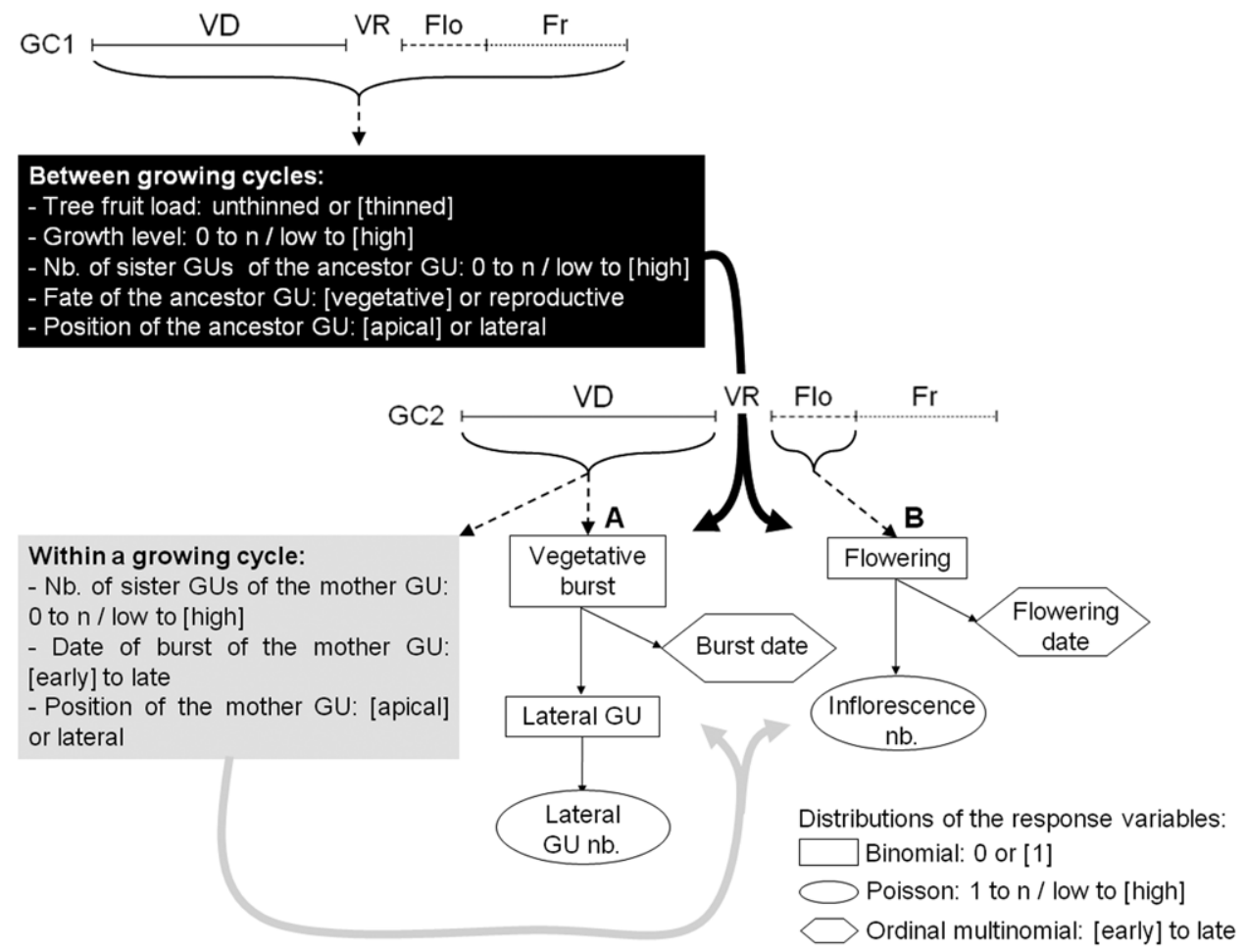

Fig. 2. Integrative vegetative and reproductive development models of mango tree superposed on the temporal succession of growing cycles (see also Fig. 1). Vegetative (A) and reproductive (B) models are represented as oriented tree graphs where each vertex corresponds to a response variable of a generalized linear model (GLM). The form of the box depends on the distribution of the response variable. Each thin solid arrow represents the conditioning of a subsequent GLM by the value 1 (true) taken by the binary response variable of a binomial model. The factors studied are figured in two rectangles corresponding to two temporal scales, 'within a growing cycle' (grey rectangle) and 'between growing cycles' (black rectangle), respectively. Each factor potentially influences each response variable (thick black and grey arrows). Modalities of each response variable or factor are listed and modalities between brackets are used as references in Tables 2 and 3. 
integrative models were built that enabled a causal analysis of the biological system.

Since apical and lateral GUs are characterized by differences in morphology and the ability to grow, flower, and set fruit (Normand et al., 2009), it was important to distinguish apical and lateral daughter GUs in the vegetative development. Consequently, the vegetative development model (Fig. 2A) was composed of four GLMs: (i) an initial binomial GLM whose response variable was the occurrence of burst of a terminal GU, i.e. the production of at least one daughter GU. When budburst occurred, there was almost always an apical daughter GU produced (except for reproductive ancestor GUs, i.e. an ancestor GU that bore at least one inflorescence). The occurrence of budburst conditioned the following two subsequent GLMs: (ii) A binomial GLM whose response variable was the occurrence of at least one lateral daughter $\mathrm{GU}$, in addition to the apical daughter GU; and (iii) a multinomial ordinal GLM whose response variable was the date of burst. The occurrence of at least one lateral daughter GU conditioned (iv) a subsequent Poisson GLM whose response variable was the number of lateral daughter GUs produced.

The reproductive development model (Fig. 2B) was composed of three GLMs: (i) an initial binomial GLM whose response variable was the occurrence of flowering of a terminal GU. The occurrence of flowering conditioned two subsequent GLMs: (ii) a Poisson GLM whose response variable was the number of inflorescences produced per GU that flowered; and (iii) a multinomial ordinal GLM whose response variable was the date of flowering (only for the second growing cycle since the data were not available for the first growing cycle).

Each response variable of a GLM (belonging either to the vegetative or to the reproductive development model) was potentially influenced by different factors. To assess the possible short- and long- distance and term effects of factors on the response variables, potential factors were evaluated at two temporal scales (the two rectangles in Fig. 2): 'within a growing cycle' (short -distance and -term) and 'between growing cycles' (long-distance and -term). Different factors were considered at each scale. In the former case (Fig. 2, 'within a growing cycle'), factors were related to the mother GU and were its number of sister GUs, its date of burst, and its position. In the second case (Fig. 2, 'between growing cycles'), factors were considered at two structural scales. The first scale was the whole tree with the tree fruit load. The second scale was the GU, with the growth level, and three factors related to the ancestor GU, its number of sister GUs, its fate, and its position. Each GLM thus associated one response variable of the vegetative (Fig. 2A) or reproductive (Fig. 2B) development model with one set of factors of the temporal scales (within or between growing cycles).
GLMs were initially specified, including order-two interactions between factors. Starting from a complete model with all the potential factors, a backward selection approach was applied that first removed non-significant interactions and then non-significant factors using Wald tests with a significance level at $P<0.01$. Then, the best model was chosen according to the Akaike Information Criterion.

All analyses were performed using $\mathrm{R}$ software version 2.13.0 ( $\mathrm{R}$ Development Core Team, 2011) with 'stats' ( $\mathrm{glm}()$ function for binomial and Poisson models) and 'MASS' (polr() function for ordinal multinomial models) packages.

\section{Results}

For the two growing cycles, Cogshall and Kensington Pride produced the highest numbers of GUs, inflorescences, and fruits (Table 1). From the first to the second growing cycle, the number of GUs and inflorescences produced per growing cycle doubled for all cultivars, whereas the number of fruits remained stable.

Tables 2 and 3 present the results of the 'within growing cycle' and 'between growing cycles' GLM analyses per cultivar and growing cycle, showing the effects of the specific factors on each response variable of vegetative and reproductive development. Interactions are not presented because it would lead to overly complex tables. For each couple response variable/factor, two types of effect were defined. The first type was a cultivar-independent effect and described the same positive or negative effect of the factor on the response variable over the four cultivars and the two growing cycles. The second type was referred to as a cultivar-dependent effect and described the same effect of the factor on the response variable for at least two cultivars over the two growing cycles. Concerning the response variable, 'date of flowering', cultivar-independent and -dependent effects were defined for the only growing cycle available.

The effects of factors on vegetative and reproductive developments within and between growing cycles, from the most to the least influential factor, are detailed below in accordance with the results presented in Tables 2 and 3, respectively. Only cultivar-independent and -dependent effects are considered

Table 1. Growth units and inflorescences per tree, flowering growth units per $\mathrm{cm}^{2}$ of trunk cross-sectional area, and fruits per tree produced per growing cycle for four mango cultivars and three growing cycles. Values are mean \pm SD. Co, Cogshall; Jo, José; Ir, Irwin; Kp, Kensington Pride. $n$, number of trees; NA, not available.

\begin{tabular}{|c|c|c|c|c|c|}
\hline Growing cycle & Cultivar & No. of GU $(n=5)$ & No. of inflorescence $(n=5)$ & No. of flowering GU $\mathrm{cm}^{-2}(n=5)$ & No. of fruit $(n=3)$ \\
\hline \multirow[t]{4}{*}{ Previous } & Co & NA & NA & $1.3 \pm 0.7$ & $23 \pm 8$ \\
\hline & Ir & NA & NA & $0.8 \pm 0.3$ & $29 \pm 1$ \\
\hline & Jo & NA & NA & $1.9 \pm 0.4$ & $28 \pm 8$ \\
\hline & $\mathrm{Kp}$ & NA & NA & $1.0 \pm 0.4$ & $51 \pm 24$ \\
\hline \multirow[t]{4}{*}{ First } & Co & $464 \pm 121$ & $293 \pm 33$ & $3.5 \pm 0.5$ & $106 \pm 12$ \\
\hline & Ir & $147 \pm 42$ & $113 \pm 37$ & $1.4 \pm 0.4$ & $69 \pm 17$ \\
\hline & Jo & $176 \pm 19$ & $124 \pm 63$ & $1.7 \pm 0.6$ & $64 \pm 32$ \\
\hline & $\mathrm{Kp}$ & $413 \pm 125$ & $392 \pm 148$ & $2.3 \pm 0.5$ & $169 \pm 6$ \\
\hline \multirow[t]{4}{*}{ Second } & Co & $835 \pm 162$ & $646 \pm 282$ & $7.0 \pm 2.4$ & $133 \pm 9$ \\
\hline & Ir & $319 \pm 127$ & $235 \pm 87$ & $2.6 \pm 0.8$ & $75 \pm 6$ \\
\hline & Jo & $334 \pm 131$ & $367 \pm 169$ & $2.8 \pm 1.4$ & $58 \pm 33$ \\
\hline & $\mathrm{Kp}$ & $932 \pm 460$ & $823 \pm 360$ & $4.7 \pm 2.0$ & $179 \pm 17$ \\
\hline
\end{tabular}


Page 6 of 14 | Dambreville et al.

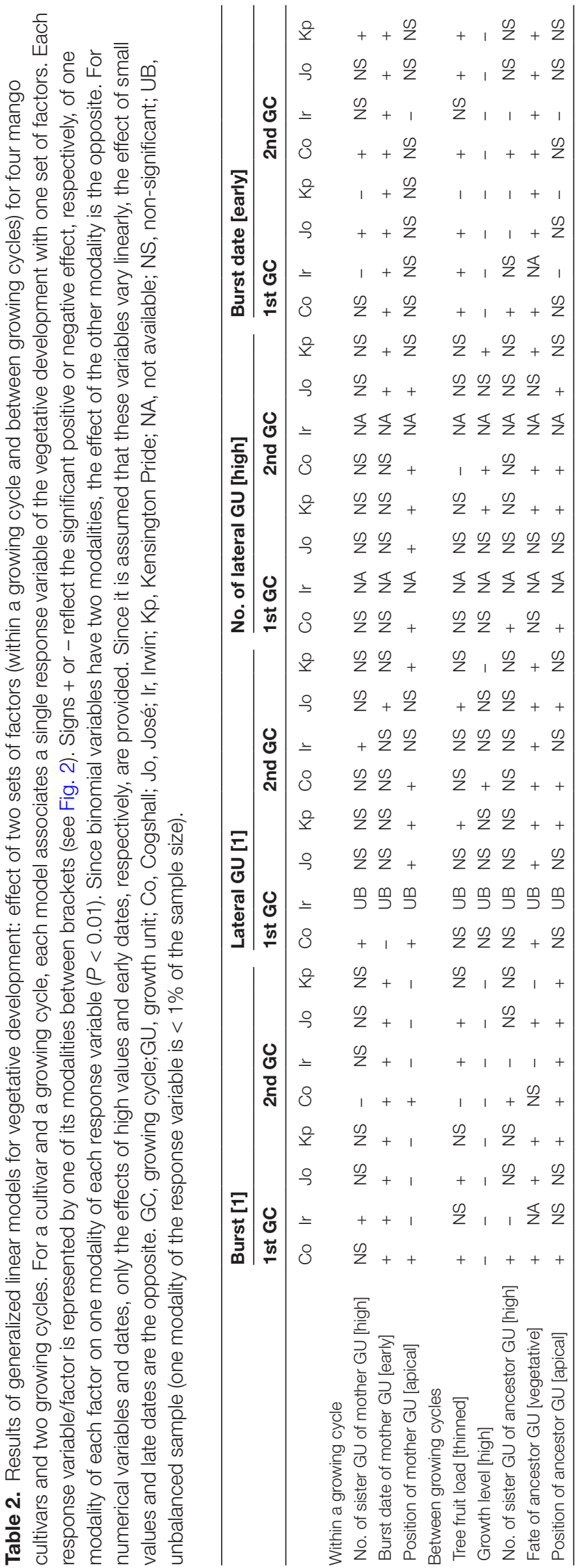

Comment citer ce document 


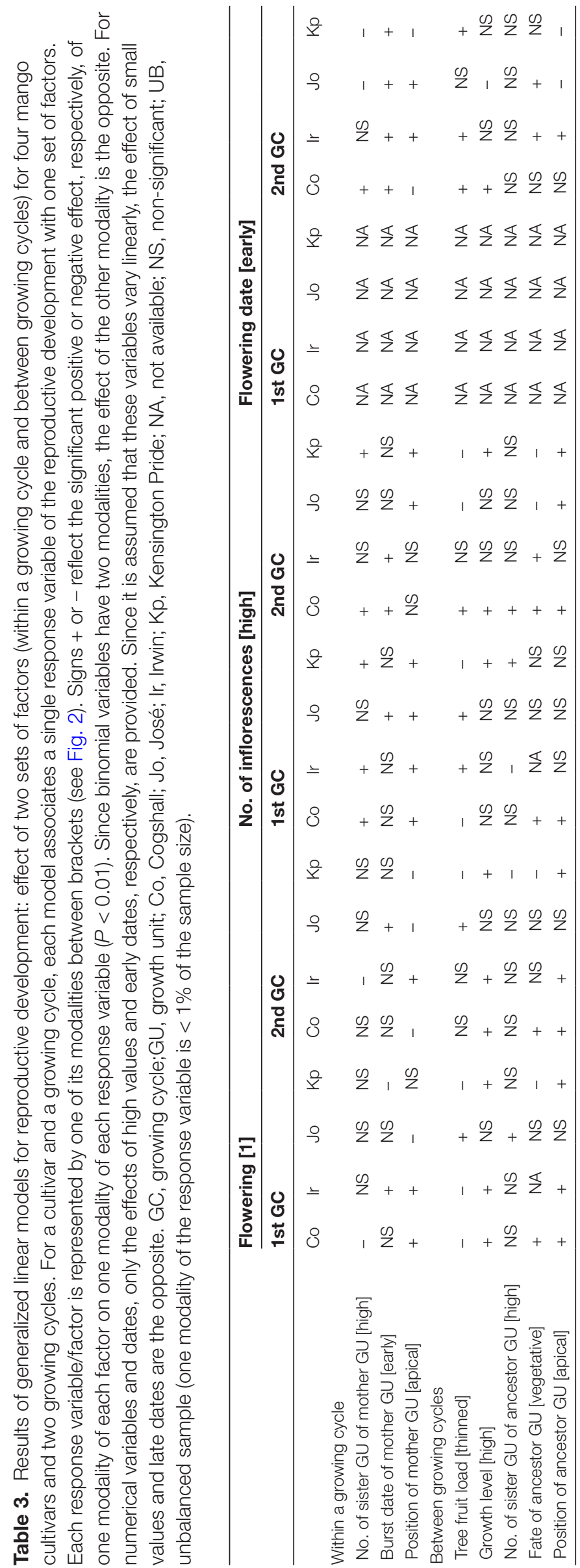


to make the results more legible. Some interesting cases are illustrated by specific graphs.

\section{Vegetative development}

\section{Within a growing cycle}

There were two cultivar-independent effects of the date of burst of the mother GU on vegetative development: an early mother GU had a higher occurrence of burst and produced early daughter GUs. This latter effect was however less clear for the second growing cycle (Fig. 3). For the first growing cycle, there was a mean difference of two months between the dates of burst of mother and daughter GUs. During the second growing cycle, vegetative development was delayed compared to the first one. In this case, the relationship between dates of burst of mother and daughter GUs could be divided into two periods (Fig. 3). During the first period, for mother GUs that appeared from August to October, all daughter GUs appeared, on average, at approximately the same time (mid-December to mid-January, except Kensington Pride, which appeared in mid-February). During the second period, for mother GUs that appeared from November to February, there was a mean difference of 2 months between the dates of burst of mother and daughter GUs.

The position of the mother GU affected three response variables of the vegetative development in a cultivar-dependent way (Table 2). First, an apical mother GU tended to repress bud burst, except for Cogshall. Second and conversely, an

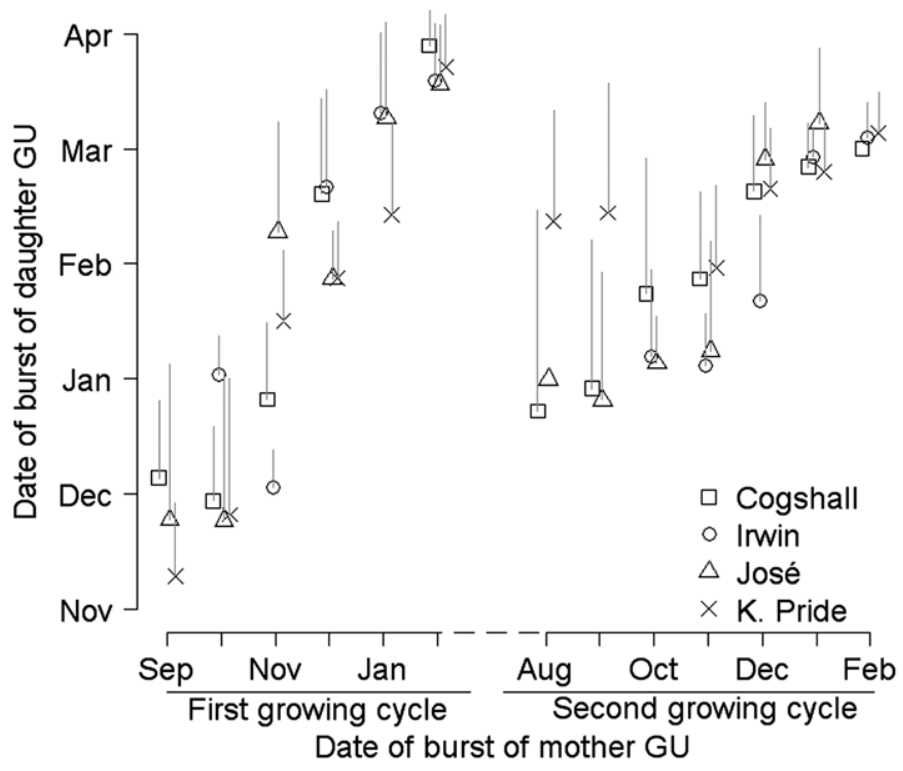

Fig. 3. Temporal influence of the mother growth unit (GU) on tree phenology. Date of burst (mean $\pm \mathrm{SD}$ ) of daughter GUs as a function of the date of burst of their mother GU in two consecutive growing cycles for four mango cultivars: Cogshall, Irwin, José, and Kensington Pride. Samples with less than 11 GUs have been ignored. Dates of burst are represented at the monthly scale. For each date of burst of the mother GU, the symbols of the four cultivars have been separated in order to visualize the standard deviations. apical mother GU tended to promote the burst of at least one lateral daughter GU for Cogshall and Kensington Pride (e.g. apical and lateral mother GUs had a relative frequency of occurrence of at least one lateral daughter GU of 0.45 and 0.07 , respectively, for Kensington Pride in the first growing cycle). For Irwin, the relative frequency of occurrence of at least one lateral daughter GU was smaller than 0.01 during the first growing cycle (UB: unbalanced sample, i.e. one modality of the response variable is $<1 \%$ of the sample size). Third, an apical mother GU tended to increase the number of lateral daughter GUs for Cogshall and José (e.g. 2.22 \pm 1.33 (mean \pm SD) lateral GUs per apical mother GU vs. $1.51 \pm 0.85$ lateral GUs per lateral mother GU for Cogshall in the first growing cycle). The number of sister GUs of the mother GU did not affect the vegetative development.

\section{Between two consecutive growing cycles}

The growth level showed two cultivar-independent effects on vegetative development. First, the higher the growth level, the lower was the occurrence of burst of GUs. Second, the higher the growth level, the later was the date of burst.

Two cultivar-independent effects of the fate of the ancestor GU on vegetative development were detected. First, a vegetative ancestor $\mathrm{GU}$ increased the occurrence of at least one lateral GU (e.g. 0.10 for reproductive ancestor GUs vs. 0.34 for vegetative ancestor GUs for Kensington Pride in the first growing cycle). For Irwin, the relative frequency of occurrence of at least one lateral GU was less than 0.01 during the first growing cycle (UB). Second, a vegetative ancestor GU increased the earliness of descendant GUs.

The position of the ancestor GU showed a cultivar-dependent effect on vegetative development: an apical ancestor GU tended to increase the occurrence of burst for Cogshall and Kensington Pride. There was a cultivar-dependent effect of the tree fruit load on the subsequent vegetative development: a thinned tree tended to promote early date of burst of descendant GUs for Cogshall and José. The number of sister GUs of the ancestor GU did not affect the vegetative development.

\section{Reproductive development}

\section{Within a growing cycle}

The date of burst of the mother GU showed a cultivarindependent effect on reproductive development: an early mother GU produced early inflorescences (Supplementary Fig. S1, available at $J X B$ online). There was a mean difference of seven months between the date of burst of a mother GU and its date of flowering. Although GLM results did not show a clear effect of the date of burst of the mother GU on the occurrence of flowering among cultivars and growing cycles, this study observed an increase followed by a decrease of the occurrence of flowering from early to late mother GUs (Supplementary Fig. S2). For Irwin, the relative frequency of the occurrence of flowering of a mother GU was high (always $>0.7$ ) and did not decrease for early and late mother GUs, compared to the other cultivars.

There was a cultivar-dependent effect of the position of the mother GU on reproductive development: an apical 
mother GU tended to increase the number of inflorescences for José and Kensington Pride (Table 3). The data showed that an apical mother GU produced more than one inflorescence on average, whereas a lateral mother GU produced only one apical inflorescence (data not shown). The effect of the position of the mother GU on its date of flowering was different between cultivars: apical GUs tended to flower later for Cogshall and Kensington Pride, whereas they tended to flower earlier for Irwin and José.

Two cultivar-dependent effects of the number of sister GUs of the mother GU on the reproductive development were detected: a high number of sister GUs tended to increase the number of inflorescences per GU (Cogshall and Kensington Pride) and to delay the date of flowering (José and Kensington Pride).

\section{Between two consecutive growing cycles}

There were two cultivar-dependent effects of the position of the ancestor GU on reproductive development. First, an apical ancestor GU tended to increase the occurrence of flowering in the subsequent growing cycle, except for José (e.g. 0.69 for apical ancestor GUs vs. 0.59 for lateral ancestor GUs for Cogshall in the second growing cycle). Second, an apical ancestor GU tended to delay the date of flowering (José and Kensington Pride).

The growth level showed a cultivar-dependent effect on the occurrence of flowering. Except for José, the higher the growth level was, the higher the occurrence of flowering of descendant GUs was. There was a cultivar-dependent effect of tree fruit load on the date of flowering of descendant GUs. Except for José, a thinned tree flowered early in the subsequent growing cycle. The fate of the ancestor GU showed a cultivardependent effect on the date of flowering. Descendant GUs stemming from a vegetative ancestor GU tended to flower earlier (Irwin and José). The number of sister GUs of the ancestor GU did not affect the reproductive development.

\section{Discussion}

Environmental factors such as temperature, light, and water availability have an influence on plant growth and development. The trees studied here were in the same orchard and were consequently submitted to the same environmental conditions. However, this study worked at the GU scale, 'and GUs are subjected' to different microclimates within a canopy. Their development, i.e. the response variables, could consequently be affected by the local microclimates. These effects were implicitly included in the statistical analyses and contributed to the residual variability.

Despite this possible source of variability, this study revealed a network of relationships between structural and temporal components of vegetative and reproductive development that were either common or specific to the four mango cultivars. They are summarized in Fig. 4. This study tried to distinguish causal relationships from other types of relationships (e.g. statistical association) using knowledge concerning in particular temporal or structural precedence of causes with respect to effects. The influence of structural and temporal factors was pinpointed within three processes: the triggering of vegetative and reproductive asynchronisms, their maintenance over time, and flowering.

\section{Structural factors are possible triggers for between- and within-tree asynchronisms through competition between organs}

At the tree scale, the competition between vegetative development and reproduction is well known, especially through the concept of costs of reproduction (Obeso, 2002). In particular, fruits are important sinks for carbohydrates and decrease the total resources available for subsequent vegetative development. In mango, several studies have highlighted the competition between fruit load and vegetative development (Scholefield et al., 1986; Jannoyer and Lauri, 2009; Shaban, 2009). The current results showed that competition conveyed a phenological dimension as well, with a main effect of fruit load in delaying both vegetative and reproductive development during the next growing cycle (Tables 2 and 3; Fig. 4). This result in mango validates a previous hypothesis in the apple that a heavy fruit load in a given year may delay vegetative development in the following year (Forshey and Elfving, 1989). Fruit load then appears as a possible trigger for between-tree vegetative and reproductive asynchronisms.

At the GU scale, the fate of the ancestor GU expressed the influence of reproduction during a given growing cycle on the development of the next growing cycle. This study showed that the reproductive fate of an ancestor GU had a significant negative effect on descendant GU development. It repressed vegetative development both structurally and temporally (Table 2; Fig 4A) and also delayed the date of flowering during the next growing cycle (Table 3; Fig. 4B). These relationships at the GU scale highlighted the fate of ancestor GUs as a possible trigger for within-tree vegetative and reproductive asynchronisms.

Apical and lateral GUs of mango are characterized by morphological and behavioural differences: an apical GU has a greater number of leaves, a larger stem, and a higher occurrence of branching, flowering, and fruiting than a lateral GU (Normand et al., 2009). This suggests an apical control exerted by the apical GU on the growth of lateral sister GUs (Wilson, 2000; Normand et al., 2009). From a structural point of view, the current study confirmed the apical control, especially on quantitative variables such as the number of lateral GUs and the number of inflorescences (Tables 2 and 3; Fig. 4). Nevertheless, no positive effect has been shown between the apical position of a mother GU and its occurrence of burst and flowering. The statistical models showed significant interactions between the two factors, position and date of burst of mother GUs, which certainly hid this positive effect. From a temporal point of view, there were cultivardependent effects of the position of the mother GUs on the date of flowering (Table 3; Fig. 4B). Moreover, there was a cultivar-dependent effect of the position of the ancestor GU on the date of flowering of its descendant GUs (Table 3; Fig. 4B). These relationships at the GU scale highlighted the position of GUs, whether within or between growing cycles, 
Page 10 of 14 | Dambreville et al.

A - Vegetative development

Temporal-temporal \& structural-structural relationships:

High

growth

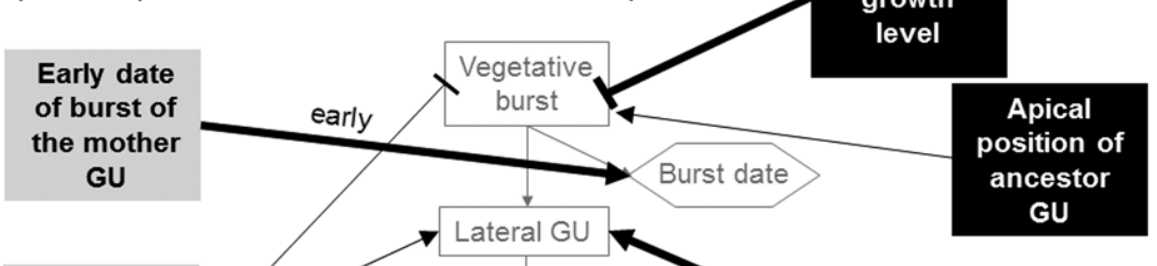

Apical position of the mother GU

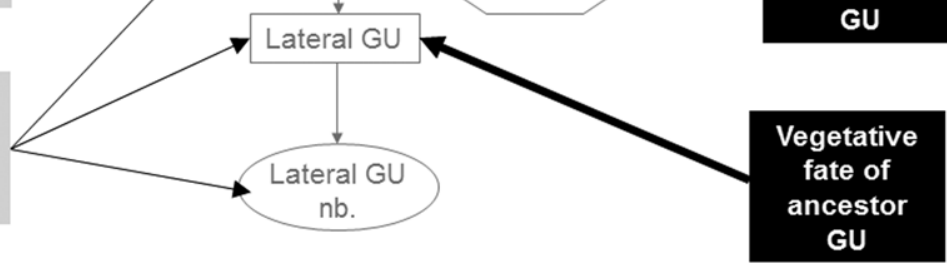

Temporal-structural relationships:

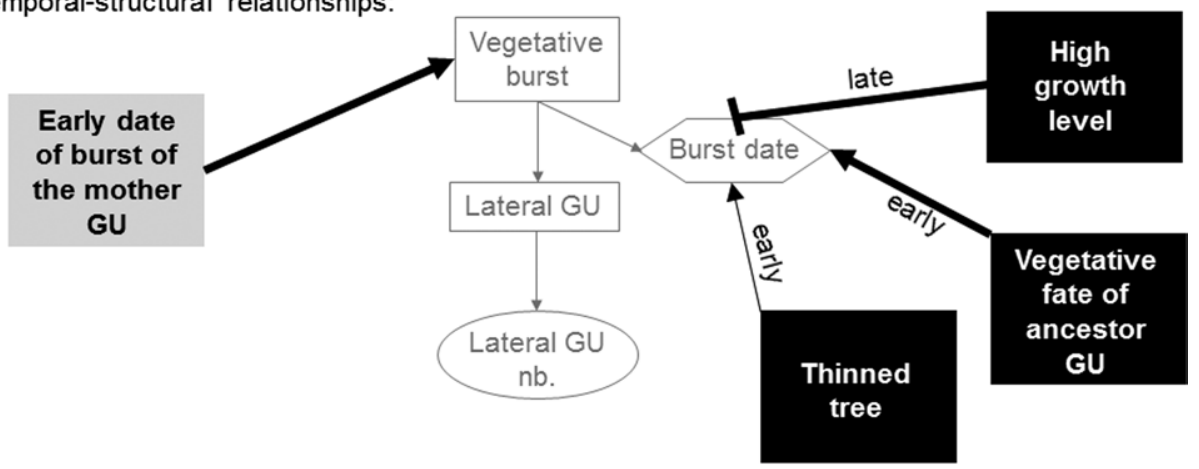

\section{B - Reproductive development}

Temporal-temporal \& structural-structural relationships:

High

growth

level

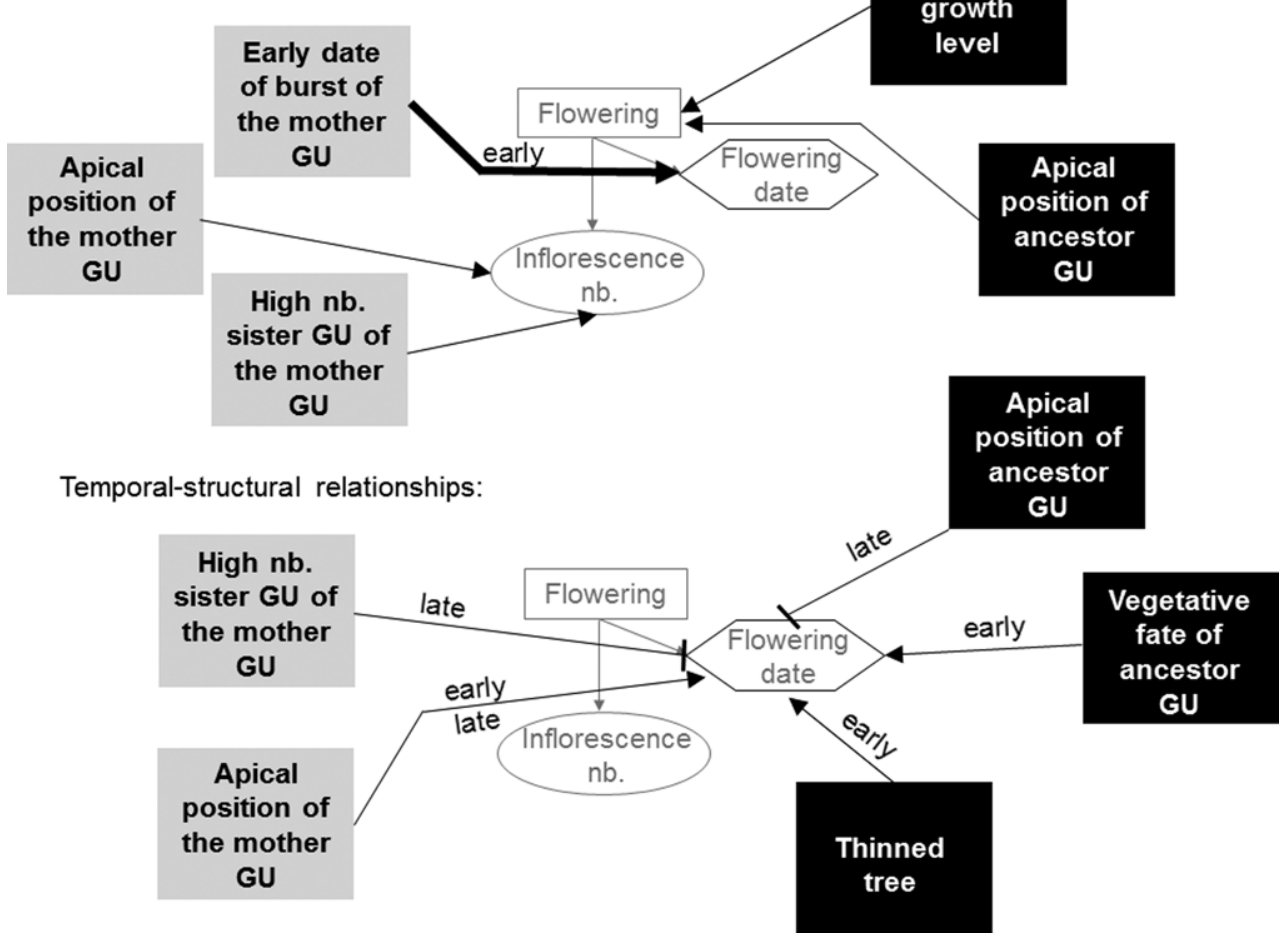

Fig. 4. Summary of the relationships between structural and temporal variables. Vegetative (A) and reproductive (B) development models are represented as oriented tree graphs where each vertex corresponds to a response variable (Fig. 2). Factors are boxed and located on the left (factors of the 'within a growing cycle' scale) and on the right (factors of the 'between growing cycles' scale) of the response variables. Each factor is represented by one of its modalities (Fig. 2). For each type of development, the upper scheme represents temporal-temporal and structural-structural relationships, and the lower scheme represents temporal-structural 
as a possible trigger for within-tree vegetative and reproductive asynchronisms.

Few studies have been made on tree development at the GU scale, and the relationships studied are most often at the first order, i.e. the effect that one GU has on the next GU through either apical growth or branching (Lauri et al., 1995; Costes et al., 2003; Costes and Guédon, 2012). The current study revealed structural and temporal effects of a GU on its descendants up to the fifth order, i.e. between an ancestor GU produced during the first growing cycle and vegetative and reproductive development of descendant GUs of the second growing cycle. These long-term and long-distance effects lead to dependencies between descendant GUs of a given ancestor GU, which could explain why phenological asynchronisms usually appear by patches of GUs often related to the same branch (Ramírez and Davenport, 2010).

\section{Endogenous rhythms are temporal components that maintain asynchronisms within the tree crown}

There was a positive effect of the date of burst of mother GUs on the date of burst of their daughter GUs, illustrating the endogenous growth rhythm within a growing cycle (Figs. 3 and 4A). However, this relationship depended on the growing cycle. During the first growing cycle, this relationship was roughly linear with a constant delay of rest, approximately 2 months, between the dates of burst of mother and daughter GUs. This delay is in agreement with the findings of Anwar et al. (2011), which described the growth of flushes in an alternate month pattern. In spite of the temperature variations during the period of vegetative development (Fig. 1A), this rather constant delay over several months (Fig. 3) suggested that in this temperature range, there was no significant effect of temperature on the endogenous rhythm of GUs within the first growing cycle. Moreover, in this experimental setting, irrigation and rainfall ensured regular water availability, eliminating the role of this factor on bud activity during the experiment. The GU-specific endogenous rhythm suggests a relative autonomy of topologically connected GUs, which could explain why asynchronisms between GUs could be maintained over one growing cycle.

During the second growing cycle, the relationship between dates of burst of mother and daughter GUs could be divided into two periods. The first one for mother GUs appeared from August to October (Fig. 3), for which the burst of daughter GUs occurred, on average, in January (February for Kensington Pride), i.e. after the first half of the harvest. The second one for mother GUs appeared from November to February, for which the 2-month delay observed during

relationships. Black arrows indicate a positive effect of the modality of the factor on the response variable, whereas black T-symbols indicate a negative effect. When the response variable is a date, the modality of the date (early or late) promoted by the factor is written on the arrow. Thick black lines indicate a cultivar-independent effect and thin black lines indicate a cultivardependent effect. the first growing cycle was almost made up for. The relationship between dates of burst of mother and daughter GUs of the first growing cycle showed the absence of a marked environmental effect on the endogenous rhythm. Since the thermal conditions were roughly the same for the first and the second growing cycles (Fig. 1A), the inhibition of growth observed during the first period of the second growing cycle could therefore not be explained by thermal conditions. It is hypothesized that a high flowering and fruiting rate at the end of the first growing cycle increased the strength of the reproductive sinks (Table 1: first growing cycle) compared to the previous growing cycle (Table 1: previous growing cycle). This interaction between reproductive development of the first growing cycle, i.e. the presence of inflorescences (for thinned and unthinned trees) and fruit (for unthinned trees), and vegetative development of the second growing cycle could be at the origin of this temporary inhibition of GU development.

Although it has been shown that an early date of burst of a mother GU increases its occurrence of flowering (Davenport, 2007; Ramírez et al., 2010b), there is still little knowledge about the relationship between the date of burst of a GU and its date of flowering. This study showed a positive relationship between these two dates (Table 3; Fig. 4B; Supplementary Fig. S1). This result agrees with the findings of Scholefield et al. (1986) and Jannoyer and Lauri (2009), showing that early GUs flower early and late GUs flower late. It supports the view that regardless of the underlying mechanisms, there is a negative relationship between the age of the GU and the requirement of fresh temperatures for floral induction in mango (Davenport, 2007). There was a delay of approximately 7 months between the date of burst of a mother GU and its date of flowering. This latter result showed how vegetative asynchronisms are able to induce reproductive asynchronisms. Such interplays are not observable in temperate trees where the ecodormancy in late winter (when chilling requirements are fulfilled but temperatures are still too cold to permit growth resumption) induces a total time reset and a synchronous flowering in the following spring.

\section{Flowering is influenced by temporal and structural components}

Over the past decades, several studies have highlighted the probable existence of a universal stimulus able to induce flowering, known as florigen, which is produced by the leaves and moves to the shoot apex through the phloem (Turck et al., 2008; Ramírez et al., 2010a). In mango, a balance between a temperature-regulated florigenic promoter and an age-regulated vegetative promoter is thought to control the induction of flowering (Davenport, 2000; Ramírez and Davenport, 2012). In subtropical regions such as Réunion Island, floral induction is primarily driven by cool temperatures (Fig. 1), with a higher occurrence of flowering as the age of the GU increases (Davenport, 2007).

This study showed that late and early mother GUs located in the terminal position at the end of the growing cycle, i.e. susceptible to flower, tended to have a lower occurrence of flowering (Supplementary Fig. S2). It can be hypothesized 
that late GUs may not be able to flower because they still contain excessive quantities of vegetative promoter (NúñezElisea and Davenport, 1995). On the other hand, early GUs, which were generally located at lower growth levels, i.e. more deeply within the canopy, may not be able to flower because of various factors such as lower light interception or natural death of the apical meristem. In addition to these possible exogenous and endogenous factors, a genotypic effect may be suggested because José and Irwin, both of which have an open canopy (Normand et al., 2009), showed contrasting abilities for GUs at lower growth levels to flower (Table 3).

A high number of sister GUs tended to increase the number of inflorescences per GU for the mother GUs that flowered (Table 3; Fig. 4B). This result suggested that the general positive relationship between the number of leaves and the number of inflorescences (Davenport et al., 2006) may also be applied to the number of branches per GU. Previous studies showed that flowering may be reduced in very vigorous trees (Forshey and Elfving, 1989). However, the current results suggested that there is a positive relationship between vegetative growth and flowering, giving more support to the idea that an increase of flowering may occur on a vigorous vegetative growth with more leaves and branches, and that it is probably genetically determined, as shown in the apple (Lauri et al., 1996; Lauri and Trottier, 2004).

This study identified causal relationships whenever possible, in particular when the factor temporally and topologically preceded the response variable. However, the temporal or topological precedence alone is not sufficient to distinguish genuine causation from spurious association caused by unknown factors, and supplementary biological assumptions are most often required to identify causal relationships with strong confidence. For example, at the GU scale, a causation chain could be drawn to explain the positive effect of the vegetative fate of the ancestor GU on the date of flowering of descendant GUs: vegetative ancestor GUs promoted early descendant GUs, which flowered early. Another example could be at the tree scale to explain why thinned trees flowered early. This study first showed that thinned trees tended to burst early and, second, that early GUs had early flowering.

These results would suggest that modifying the structural component of the tree, e.g. through pruning to affect the proportion of apical vs. lateral GUs, may eventually lead to various temporal displays of vegetative or reproductive development. This may be of practical interest at both the agronomic and crop protection levels. In the former case, it opens the possibility of better adapting the harvest period to market demand. In the latter case, this type of measure may be a way to limit pest infestations and pathogen infections, satisfying the increasing demand for low phytosanitary chemical inputs in fruit tree orchards (Lauri, 2008; Simon et al., 2012).

Environmental parameters such as air temperature are important factors for regulating plant flowering (Corbesier and Coupland, 2006). In the context of climate change and its impact on plants, these results suggest that phenological studies should better integrate within-tree variability and the respective weights of the environment and of endogenous factors such as the structural and temporal components quantified here.

\section{Supplementary material}

Supplementary data are available at $J X B$ online.

Supplementary Fig. S1. Temporal influence of the date of burst of a mother GU on its date of flowering for four mango cultivars.

Supplementary Fig. S2. Temporal influence of the date of burst of a mother GU on the relative frequency of the occurrence of flowering during two consecutive growing cycles for four mango cultivars.

\section{Acknowledgements}

We thank Clarisse Magne, Armelle Renard, Doralice Jessu, Philippe Cabeu, Marie Darnaudery and Abdoul Kowir Pambo Bello for their helpful contributions to field work and the initial statistical analyses. We also thank two anonymous reviewers for their helpful comments and suggestions. This work was funded by CIRAD, the French government, the Regional Council of Réunion Island, and the European Agricultural Fund for Rural Development (EAFRD, No111.34).

\section{References}

Anwar R, Ahmad S, Rajwana IA, Khan AS, Memon N, Nafees M. 2011. Phenological growth patterns and floral malformation of mango (Mangifera indica L.) tree under subtropical climate. Pakistan Journal of Agricultural Sciences 48, 109-115.

Barthelemy D, Caraglio Y. 2007. Plant architecture: a dynamic, multilevel and comprehensive approach to plant form, structure and ontogeny. Annals of Botany 99, 375-407.

Bell AD. 1991. Plant form: an illustrated guide to flowering plant morphology. New York: Oxford University Press.

Bonhomme R. 2000. Bases and limits to using 'degree.day' units. European Journal of Agronomy 13, 1-10.

Borchert R. 1991. Growth periodicity and dormancy. In: AS Raghvendra, ed, Physiology of trees . New York: Wiley, pp 221-245.

Bradshaw HD Jr, Stettler RF. 1995. Molecular genetics of growth and development in Populus. IV. Mapping QTLs with large effects on growth, form, and phenology traits in a forest tree. Genetics 139, 963-973.

Celton J, Martinez S, Jammes M, Bechti A, Salvi S, Legave J, Costes E. 2011. Deciphering the genetic determinism of bud phenology in apple progenies: a new insight into chilling and heat requirement effects on flowering dates and positional candidate genes. New Phytologist 192, 378-392.

Chacko EK. 1986. Physiology of vegetative and reproductive growth in mango (Mangifera indica L.) trees. In: Proceedings of the First Australian Mango Research Workshop. Melbourne: CSIRO, pp 54-70.

Champagnat P, Barnola P, Lavarenne S. 1971. Premières recherches sur le déterminisme de l'acrotonie des végétaux ligneux. Annales des Sciences Forestières 28, 5-22.

Corbesier L, Coupland G. 2006. The quest for florigen: a review of recent progress. Journal of Experimental Botany 57, 3395-3403. 
Costes E. 1995. Litchi tree architecture and flowering: considerations on controlling biennial bearing. Fruits 50, 191-204.

Costes E, Sinoquet H, Kelner JJ, Godin C. 2003. Exploring withintree architectural development of two apple tree cultivars over 6 years. Annals of Botany 91, 91-104.

Costes E, Guédon Y. 2012. Deciphering the ontogeny of a sympodial tree. Trees - Structure and Function 26, 865-879.

Dambreville A, Normand F, Lauri PÉ. 2013. Plant growth co-ordination in natura: a unique temperature-controlled law among vegetative and reproductive organs in mango. Functional Plant Biology, 40, 280-291.

Davenport TL. 2000. Processes influencing floral initiation and bloom: the role of phytohormones in a conceptual flowering model. HortTechnology 10, 733-739.

Davenport TL. 2007. Reproductive physiology of mango. Brazilian Journal of Plant Physiology 19, 363-376.

Davenport TL, Ying Z, Kulkarni V, White TL. 2006. Evidence for a translocatable florigenic promoter in mango. Scientia Horticulturae 110, 150-159.

Forshey CG, Elfving DC. 1989. The relationship between vegetative growth and fruiting in apple trees. Horticultural Reviews 11, 229-287.

Gerbaud P. 2011. Mango. FruiTrop 186, 18-58.

Godin C, Costes E, Sinoquet H. 1999. A method for describing plant architecture which integrates topology and geometry. Annals of Botany 84, 343-357.

Goguey T. 1997. Architectural approach of the mechanisms of canopy growth and flowering of mango trees. Acta Horticulturae 455, 124-131.

Guédon Y, Legave JM. 2008. Analyzing the time-course variation of apple and pear tree dates of flowering stages in the global warming context. Ecological Modelling 219, 189-199.

Hallé F, Martin R. 1968. Étude de la croissance rythmique chez I'hévéa (Hevea brasiliensis Müll. -Arg., Euphorbiacées, Crotonoïdées). Adansonia 8, 475-503.

Hallé F, Oldeman RA, Tomlinson PB. 1978. Tropical trees and forests. An architectural analysis . Berlin: Springer-Verlag.

Jannoyer M, Lauri PE. 2009. Young flush thinning in Mango (cv. Cogshall) controls canopy density and production. Acta Horticulturae 820, 395-402.

Kikuzawa K, Koyama H, Umeki K, Lechowicz MJ. 1996. Some evidence for an adaptive linkage between leaf phenology and shoot architecture in sapling trees. Functional Ecology 10, 252-257.

Körner C, Basler D. 2010. Phenology under global warming. Science 327, 1461-1462.

Lauri PÉ. 2007. Differentiation and growth traits associated with acrotony in the apple tree (Malus $\times$ domestica, Rosaceae). American Journal of Botany 94, 1273-1281.

Lauri PÉ. 2008. Trends in apple training in France - an architectural and ecophysiological perspective. Acta Horticulturae 772, 483-490.

Lauri PÉ, Trottier C. 2004. Patterns of size and fate relationships of contiguous organs in the apple (Malus domestica) crown. New Phytologist 163, 533-546.
Lauri PÉ, Térouanne É, Lespinasse JM. 1996. Quantitative analysis of relationships between inflorescence size, bearing-axis size and fruitset - an apple tree case study. Annals of Botany 77, 277-286.

Lauri PÉ, Térouanne É, Lespinasse JM, Regnard JL, Kelner JJ. 1995. Genotypic differences in the axillary bud growth and fruiting pattern of apple fruiting branches over several years - an approach to regulation of fruit bearing. Scientia Horticulturae 64, 265-281.

Lieth H. 1974. Phenology and seasonality modeling . Berlin: Springer-Verlag.

Marco DE, Páez SA. 2002. Phenology and phylogeny of animaldispersed plants in a dry Chaco forest (Argentina). Journal of Arid Environments 52, 1-16.

Monselise SP, Goldschmidt EE. 1982. Alternate bearing in fruit trees. Horticultural Reviews 4, 128-173.

Newstrom LE, Frankie GW, Baker HG. 1994. A new classification for plant phenology based on flowering patterns in lowland tropical rain forest trees at La Selva, Costa Rica. Biotropica 26, 141-159.

Normand F, Pambo Bello AK, Trottier C, Lauri PÉ. 2009. Is axis position within tree architecture a determinant of axis morphology, branching, flowering and fruiting? An essay in mango. Annals of botany 103, 1325-1336.

Núñez-Elisea R, Davenport TL. 1995. Effect of leaf age, duration of cool temperature treatment, and photoperiod on bud dormancy release and floral initiation in mango. Scientia Horticulturae 62, 63-73.

Obeso JR. 2002. The costs of reproduction in plants. New Phytologist 155, 321-348.

Pearl J. 2009. Causality: models, reasoning and inference, 2nd edn. New York: Cambridge University Press.

R Development Core Team. 2011. R: a language and environment for statistical computing. Vienna, Austria: R Foundation for Statistical Computing.

Ramírez F, Davenport TL. 2010. Mango (Mangifera indica L.) flowering physiology. Scientia Horticulturae 126, 65-72.

Ramírez F, Davenport TL. 2012. Reproductive biology (physiology) - the case of mango. In: SG Valavi, K Rajmohan, JN Govil, KV Peter, G Thottappilly, eds, Mango: volume 1 production and processing technology . USA: Studium Press. pp 56-81.

Ramírez F, Davenport TL, Fischer G. 2010a. The number of leaves required for floral induction and translocation of the florigenic promoter in mango (Mangifera indica L.) in a tropical climate. Scientia Horticulturae 123, 443-453.

Ramírez F, Davenport TL, Fischer G, Augusto Pinzon JC. 2010b. The stem age required for floral induction of synchronized mango trees in the tropics. HortScience 45, 1453-1458.

Sakai S. 2001. Phenological diversity in tropical forests. Population Ecology 43, 77-86.

Scarrone F. 1969. Recherche sur les rythmes de croissance du Manguier et de quelques végétaux ligneux Malagasy. PhD Thesis, Clermont-Ferrand University, France.

Scholefield PB, Oag DR, Sedgley M. 1986. The relationship between vegetative and reproductive development in the mango in northern Australia. Australian Journal of Agricultural Research 37, 425-433. 
Page 14 of 14 | Dambreville et al.

Shaban AEA. 2009. Vegetative growth cycles of some mango cultivars in relation to flowering and fruiting. World Journal of Agricultural Sciences 5, 751-759.

Simon S, Morel K, Durand E, Brevalle G, Girard T, Lauri PE. 2012. Aphids at crossroads: when branch architecture alters aphid infestation patterns in the apple tree. Trees 26, 273-282.

Smith-Ramírez C, Armesto JJ, Figueroa J. 1998. Flowering, fruiting and seed germination in Chilean rain forest myrtaceae: ecological and phylogenetic constraints. Plant Ecology 136, 119-131.

Turck F, Fornara F, Coupland G. 2008. Regulation and identity of florigen: FLOWERING LOCUS T moves center stage. Annual Review of Plant Biology 59, 573-594.

Wilson BF. 2000. Apical control of branch growth and angle in woody plants. American Journal of Botany 87, 601-607. 